\title{
Acute presentation of choriocarcinoma: a case study and review of the literature
}

\author{
Andrew Worster, MD;* Sangita Sharma, MD; † Farouk Mookadam, MD; $\ddagger$ John Opie, MD*
}

\begin{abstract}
We report an unusual case of a 27-year-old male with an acute presentation of choriocarcinoma. The patient presented with unstable vital signs, severe anemia and a widened arterial pulse pressure following a several day history of testicular pain. He was subsequently diagnosed as having testicular choriocarcinoma with multiple hepatic metastases and large hemorrhagic para-aortic lymph nodes. The widened pulse pressure persisted during fluid resuscitation and correction of both the anemia and hypotension, and only narrowed after the initiation of chemotherapy. A literature review indicates that metastatic testicular choriocarcinoma is a rare but aggressive malignancy that often presents with acute symptoms and signs that cause patients to seek emergency care. We summarize the reported cases of "acute" testicular choriocarcinoma presentation and briefly discuss its relationship to widened arterial pulse pressure.
\end{abstract}

Key words: choriocarcinoma; testicular neoplasms; pulse pressure; shock; emergency medicine.

\section{RÉSUMÉ}

Nous présentons un cas inhabituel de présentation aiguë d'un choriocarcinome chez un homme âgé de 27 ans. Le patient avait été reçu à l'urgence pour des signes vitaux instables, une anémie sévère et une augmentation de sa tension artérielle différentielle découlant d'une douleur testiculaire installée depuis plusieurs jours. On diagnostiqua par la suite un choriocarcinome du testicule accompagné de métastases hépatiques multiples et de ganglions para-aortiques tuméfiés et hémorragiques. L'augmentation de la tension artérielle différentielle persista au cours de la réanimation liquidienne et de la correction de l'anémie et de l'hypotension et diminua seulement après le début de la chimiothérapie. Une revue de la littérature indique que le choriocarcinome métastatique du testicule est un cancer rare mais virulent souvent accompagné de signes et symptômes aigus qui incitent le patient à obtenir des soins d'urgence. Nous résumons les cas signalés de présentation "aiguë» de choriocarcinome du testicule et discutons brièvement de sa relation avec l'augmentation de la tension artérielle différentielle.

\section{Introduction}

Testicular cancer is a general term for several distinct but related neoplasms. ${ }^{1}$ It constitutes only $1 \%$ of cancers in males overall, but is the most common malignant neoplasm in men aged 15 to 35 years, with an incidence of 2.1 cases per 100000 males and 4 times greater incidence in white males than in black males. ${ }^{1-3}$ Germ cell tumours (GCTs), of which choriocarcinoma is a type, account for nearly $93 \%$ of all primary testicular malignancies. Although pure choriocarcinoma accounts for only less than $1 \%$ of all testicular tumours, it is a common component of

*Departments of Emergency Medicine and *†Medicine, Hamilton Health Sciences Corporation and McMaster University, Hamilton, Ont., and $¥$ Department of Cardiovascular Disease, The Mayo Clinic, Rochester, Minn.

Received: Mar. 30, 2001; final submission: Dec. 6, 2001; accepted: Dec. 11, 2001

This article has been peer reviewed. 
other testis tumours and its syncytiotrophoblastic cells contain plasma chorionic gonadotrophin ( $\beta$-hCG), which is used as a tumour marker for diagnosis, grading and treatment response. ${ }^{46}$

In most cases, malignant testicular tumours manifest as painless testicular masses; however, patients may also present with testicular pain secondary to bleeding or infarction in the tumour, symptoms from metastases, or symptoms from elevated levels of $\beta$-hCG. ${ }^{7}$ Emergency physicians should be aware that testicular cancer can first present as a life-threatening disorder and that successful resuscitation may depend upon treatment of the underlying malignancy. In addition, physicians should know that specific imaging modalities and laboratory tests, such as lactic dehydrogenase (LDH), $\alpha$-fetoprotein (AFP) and $\beta$-hCG, will help identify the underlying malignancy and expedite effective therapy.

\section{Case report}

A 27-year-old male arrived at the emergency department (ED) by ambulance with jaundice and hypovolemic shock. He gave a 1-week history of left testicular pain, diagnosed by his family physician as epididymitis. After ciprofloxacin was initiated, the patient had developed abdominal pain and dark urine; thus, his treatment was changed to doxycycline. He felt increasingly unwell, with lethargy, fatigue and abdominal pain, and on the morning of his presentation to the ED, he experienced a syncopal episode.

\section{Physical exam}

In the ED, he was alert and oriented but appeared ill, with pallor and jaundice. Vital signs revealed a tympanic temperature of $36^{\circ} \mathrm{C}$, a respiratory rate of 24 breaths/min, a thready pulse at 143 beats/min and a blood pressure (BP) of $121 / 60 \mathrm{~mm} \mathrm{Hg}$, which quickly fell to $82 / 40 \mathrm{~mm} \mathrm{Hg}$. Examination of the cardiovascular system revealed a reduced jugular venous pressure and a hyper dynamic apex, with no abnormal heart sounds or bruits. The respiratory exam was unremarkable except for shallow respirations, and the abdomen was distended with right upper quadrant tenderness. Hepatomegaly and ascites were also noted, but there was no evidence of peritonitis. Scrotal examination revealed a tender left testicle with no swelling or testicular masses. Rectal examination was negative for melena, masses or occult blood.

\section{Treatment}

A $1 \mathrm{~L}$ normal saline bolus was rapidly infused, and the BP rose from $80 \mathrm{~mm} \mathrm{Hg}$ by palpation to $121 / 60 \mathrm{~mm} \mathrm{Hg}$.
Transfusion was initiated within 90 minutes of arrival and, after 2 units of packed red blood cells, BP had risen to 140/75 mm Hg.

\section{Laboratory investigations}

Significantly abnormal results included a leukocyte count of $31.6 \times 10^{9} / \mathrm{L}$ with a marked shift to the left, a hemoglobin level of $67 \mathrm{~g} / \mathrm{L}$ with target cells and fragments, a plasma fibrinogen level of 5.2 (normal 1.6-4.2) g/L, serum levels of calcium 2.11 (normal 2.20-2.58) $\mathrm{mmol} / \mathrm{L}$, albumin 26 (normal 35-50) g/L, phosphate 1.59 (normal 0.80-1.45) $\mathrm{mmol} / \mathrm{L}$, total bilirubin 43 (normal 2-18) $\mu \mathrm{mol} / \mathrm{L}$, conjugated bilirubin 22 (normal $<4$ ) $\mathrm{mmol} / \mathrm{L}$, aspartate aminotransferase (AST) 219 (normal <35) U/L, alanine aminotransferase (ALT) 121 (normal <35) U/L, $\gamma$-glutamyl transferase (GGT) 94 (normal <45) U/L, lactate dehydrogenase 1926 (normal 100-220) U/L, and quantitative $\beta$-hCG 19237 (normal <2) IU/L.

Computerized tomography (CT) of the abdomen demonstrated hepatic metastases with necrosis, as well as large hemorrhagic para-aortic lymph nodes and free fluid in the abdomen. There were bilateral metastatic pleural and parenchymal nodules in the chest, but no abnormal mediastinal lymph nodes. A contrast CT of the head was normal, and scrotal ultrasound was consistent with choriocarcinoma of the testes.

Two days later, the patient was started on bleomycin, etoposide and cisplatinum. After 2 chemotherapy treatments, his pulse pressure returned to normal $(120 / 80 \mathrm{~mm} \mathrm{Hg})$.

\section{Discussion}

Choriocarcinomas are the most aggressive and rapidly growing germ cell tumours. They spread via blood and lymphatics, with early hematogenous dissemination to lungs, liver, brain and other visceral sites. Because the average diagnostic delay is 4 to 6 months after symptom onset, patients often present initially with acute disorders resulting from hemorrhage or necrosis of the primary tumours or their metastases. ${ }^{8.9}$ Published case studies show that choriocarcinoma may present with 1 or more of the following complications.

\section{Hematologic}

Choriocarcinoma and other testicular cancers often cause life-threatening or fatal bleeding problems. These include hemoptysis, hemetemesis, melena and epistaxis, as well as hemorrhage into closed spaces such as the scrotum, brain or peritoneum..$^{10-16}$ The tumours themselves are highly vascular $^{17}$ and can bleed continuously despite small size. ${ }^{12}$ In 
addition, hepatic metastases may lead to clotting factor deficiency (II, V, VII and X), and choriocarcinoma has been associated with consumption coagulopathy and thrombocytopenia, which aggravate tumour-related bleeding. ${ }^{18}$

\section{Cardiovascular}

Choriocarcinoma may invade blood vessels throughout the body, causing large vessel occlusion or, in rare cases, arteriovenous shunts. A retrospective study of 1 germ cell tumour database showed that $9.3 \%$ of 333 male patients with metastatic disease had radiographic evidence of inferior vena cava obstruction. ${ }^{19}$ These patients often had leg swelling and dilated abdominal wall veins, but $29 \%$ had thromboembolic complications, including 1 fatal pulmonary embolism. ${ }^{19}$

\section{Respiratory}

Choriocarcinoma spreads hematogenously to the lungs, with resulting pulmonary embolism, pulmonary edema, adult respiratory distress syndrome (ARDS), pulmonary hypertension or cor pulmonale..$^{20-25}$ Patients who develop cough, chest pain, dyspnea, hemoptysis, hypoxemia or evidence of pulmonary hypertension and acute right heart strain therefore require thorough evaluation. ${ }^{24-26}$

\section{Endocrine}

Patients with choriocarcinoma typically have elevated $\beta$ hCG levels. ${ }^{4,5}$ Because the $\beta$-hCG molecule has a direct thyroid-stimulating effect, these patients may present with hyperthyroidism..$^{27,28}$ Thyroid symptoms are usually mild, even in the face of widespread choriocarcinoma, ${ }^{28}$ but range from subtle exopthalmos to fulminant throtoxicosis. ${ }^{7.27}$ Thyroid enlargement is unlikely, and in 1 series the most common findings were tachycardia, hypertension and systolic flow murmur. ${ }^{7}$ In general, hyperthyroidism resolves as $\beta$-hCG levels fall after chemotherapy. Specific anti-thyroid medication is rarely required.

\section{Gastrointestinal}

Acute or chronic gastrointestinal bleeding may occur in patients with metastatic choriocarcinoma, ${ }^{12,29}$ and 1 case of small-bowel obstruction due to jejunal intussusception has also been reported. ${ }^{29}$

\section{Neurologic}

Brain metastases are common; therefore, various neurological syndromes, including visual loss, are reported, ${ }^{30,31}$ and testicular choriocarcinoma may present initially with intracerebral hemorrhages or massive, sudden intratumoural hemorrhage. ${ }^{14,15}$

\section{Widened pulse pressure}

The arterial pulse pressure is the difference between systolic and diastolic pressures. Normal pulse pressure is between $20-60 \mathrm{~mm} \mathrm{Hg}{ }^{32,33}$ A widened arterial pulse pressure occurs in conditions in which the arterial compliance increases disproportionately to the stroke volume. Similarly, a narrowing of the arterial pulse pressure is seen when the stroke volume is increased without a corresponding increase in the arterial compliance or as the compliance decreases without a corresponding decrease in the stroke volume. In short, a widened arterial pulse pressure occurs when there is an increase in the arterial compliance-tostroke volume ratio. ${ }^{33}$ Other reported causes of widened pulse pressure include exercise, anemia, vasogenic shock, beriberi, thyrotoxicosis, aortic regurgitation, patent ductus arteriosus and arteriovenous shunting.

\section{Summary}

A patient with metastatic testicular choriocarcinoma presented with unstable vital signs, anemia and a widened arterial pulse pressure following 1 week of testicular pain. The initial presentation of choriocarcinoma is often an acute, life-threatening condition as the result of advanced, widespread metastases. Our patient's case is unusual in that he presented with a widened arterial pulse pressure in the presence of shock. ${ }^{34}$ The widened arterial pulse pressure was likely due to arteriovenous shunts from multiple metastatic lesions. In fact, trauma and neoplasms are responsible for most cases of arteriovenous shunts involving the liver. ${ }^{35}$

Emergency physicians should be aware that testicular neoplasms and choriocarcinoma may be the cause of hemorrhagic shock. Using investigations that are readily available in most EDs, the emergency physician can identify the underlying malignancy as the causative agent and direct therapy appropriately.

Competing interests: None declared.

Acknowledgement: This paper was funded by Hamilton Health Sciences, Hamilton, Ont.

\section{References}

1. Schottenfeld D, Warshauer ME, Sherlock S, Zauber AG, Leder M, Payne R. The epidemiology of testicular cancer in young adults. Am J Epidemiol 1980;112:232-46.

2. Wingo PA, Tong T, Bolden S. Cancer statistics, 1995. CA Cancer J Clin 1995;45:8-30.

3. Mostofi FK. Testicular tumors: epidemiologic, etiologic and pathologic features. Cancer 1973;32:1186-201. 
4. Zondek B. Versuch einer biologischen (hormonalen) diagnostik beim malignen hodentumor. Chirug 1930;2:1072-80.

5. Bosl GJ, Lange PH, Nochomovitz LE, Goldmann A, Fraley EE, Rosai J, et al.. Tumor markers in advanced nonseminomatous testicular cancer. Cancer 1981;47(3):572-6.

6. Catalona WJ. Tumor markers in testicular cancer. Urol Clin N America 1979;6:613-28.

7. Giralt SA, Dexeus F, Amato R, Sella A, Logothetis C. Hyperthyroidism in men with germ cell tumors and high levels of beta-human chorionic gonadotropin. Cancer 1992;69:1286-90.

8. Cotran. Robbins pathologic basis of disease. 6th ed. Philadelphia: WB Saunders Company; 1999.

9. Richie JP. Advances in the diagnosis and treatment of testicular cancer. Cancer Invest 1993;11:670-5.

10. Stokes EW, Perkins C. Testicular choriocarcinoma: an unusual presentation as occult gastrointestinal blood loss. J Adoles Health Care 1989;10:146-50.

11. Benditt JO, Farber HW, Wright J,Karnad AB. Pulmonary hemorrhage with diffuse alveolar infiltrates in men with high-volume choriocarcinoma. Ann Intern Med 1988;108:674-5.

12. Tariq M, Glucman P, Thebe P. Metastatic testicular teratoma of the nasal cavity: a rare cause of severe intractable epistaxis. J Laryngol Otol 1998;112:1078-81.

13. Cutajar CL. Spontaneous rupture of testicular teratoma. Br Med J 1972;1:154-5.

14. Nishizaki T, Orita T, Tsuha M, Wakuta Y, Fujii M, Ito H. Brain metastasis of testicular tumor with massive hemorrhage - report of two cases. Neurol Med Chir (Tokyo) 1991;31:586-9.

15. Kidd D, Plant GT, Scaravilli F, McCartney AC, Stanford M, Graham EM. Metastatic choriocarcinoma presenting as multiple intracerebral haemorrhages: the role of imaging in the elucidation of the pathology. J Neurol Neurosurg Psychiatry 1998;65:939-41.

16. Watkins GL. Massive hemoperitoneum resulting from rupture of a seminoma in an undescended testicle. J Urol 1970;103:447-8.

17. Fidler IJ. Critical factors in the biology of human cancer metastasis: twenty-eighth G.H.A. Clowes memorial award lecture. Cancer Res 1990;50:6130-8.

18. Lox CD, Trevino J. Abnormal hematological indices associated with metastatic choriocarcinoma in a young man. J Med 1983;14:95-101.

19. Hassan B, Tung K, Weeks R, Mead GM. The management of inferior vena cava obstruction complicating metastatic germ cell tumors. Cancer 1999;85:912-8.

20. Bone RC, et al. Pulmonary and critical care medicine [electronic resource]: your single-source reference library on CD-ROM.
1998 ed. St. Louis: Mosby-Year Book, Inc; 1998.

21. Haab F, Cour F, Boutan Laroze A, Squara P, Lucas G. Testicular neoplasm presenting as a major pulmonary embolism. Eur Urol 1996; 29:494-6.

22. Karila-Cohen D, Mentec H, Bleichner G. Testicular choriocarcinoma revealed by a localized pulmonary edema: a case report. Intensive Care Med 1995;21:1036-8.

23. McGowan MP, Pratter MR, Nash G. Primary testicular choriocarcinoma with pulmonary metastases presenting as ARDS. Chest 1990;97:1258-9.

24. Winterbauer RH, Elfenbein IB, Ball WC: Incidence and clinical significance of tumor embolization to the lungs. Am J Med 1968;45:271-90.

25. Kupari M, Laitinen L, Hekali P, Luomanmaki K. Cor pulmonale due to tumor cell embolization. Acta Med Scand 1984;210:507-10.

26. Kane RD, Hawkins HK, Miller JA, Noce PS. Microscopic pulmonary tumor emboli associated with dyspnea. Cancer 1975; $36: 1473-82$.

27. Gleason PE, Elliott DS, Zimmerman D, Smithson WA, Kramer SA. Metastatic testicular choriocarcinoma and secondary hyperthyroidism: case report and review of the literature. J Urol 1994;151:1063-4.

28. Goodarzi MO, Van Herle AJ. Thyrotoxicosis in a male patient associated with excess human chorionic gonadotropin production by germ cell tumor. Thyroid 2000;10:611-9.

29. Hofflander R, Beckes D, Kapre S, Matolo N, Liu S. A case of jejunal intussusception with gastrointestinal bleeding caused by metastatic testicular germ cell cancer. Dig Surg 1999;16:439-40.

30. Yoshida S, Morii K. Brain metastasis from germinal tumors of the testis. Case report. J Neurosurg 1990;88:761-3.

31. Bettocchi C, Coker CB, Traficante A, Selvaggi FP. Testicular cancer presenting as loss of vision. Br J Urol 1995;76:519-20.

32. Roberts JR. Clinical procedures in emergency medicine. 3rd ed. Philadelphia: WB Saunders; 1998.

33. Guyton AC, Hall JE. Textbook of medical physiology. 9th ed. Philadelphia: WB Saunders; 1996.

34. Murray JC, Oshman D, Steuber CP. Diastolic runoff with widened arterial pulse pressure in an adolescent with widely metastatic testicular choriocarcinoma. Pediatr Cardiol 1995;16:145-6.

35. Kitamura K. TPN-induced fulminant beriberi: a report on our experience and a review of the literature. Surg Today 1996;26:769-76.

Correspondence to: Dr. Andrew Worster, Division of Emergency Medicine, Hamilton Health Sciences, 237 Barton St. E, Hamilton ON L8N 3Z5; 905 521-2100 x73136, fax 905 527-7051, aworster@ rogers.com 